\section{Mascons, Marid and Sinuous Rilles-A Postulated Igneous Origin}

Muller and Sjogren ${ }^{1}$ have correlated seven mascons with mare regions and suggest that they represent buried asteroids formed by low velocity impact ${ }^{2}$. Two further mascons have been located by Campbell et al. ${ }^{3}$ in Marginis and Occultum, a possible ancient mare. We have compared the locations with the distribution of about 100 sinuous rilles, plotted by Peale et al. ${ }^{4}$. Most of the rilles are along mare margins, and Peale et al. suggest they are ancient stream valleys.

Five of the mascons underlie mare areas where sinuous rilles are prevalent (Imbrium, Serenitatis, Humorum, Aestuum-Medii and Orientale). This, plus their concen. tration on the Moon's near side, suggests a common igneous origin. Impact mare-mascons would be randomly distributed unless they occurred simultaneously from an asteroid swarm. But erater counts and the varying sharpness of mare features indicate different mare ages.

Mascons may be subsurface magma chambers or batholiths which would be denser than the surrounding protolunar particulate matter from which they formed. Maria may be huge caldera-type collapse features filled with extruded lava or tephra from the underlying magma. Sinuous rilles, which often widen as they rum downhill and originate from craterlets on small cones at mare edges, may be channels formed by tephra flows which spread out before depositing their particles thinly beyond the cnds of rilles ${ }^{5}$. Sinuous rilles with rows of craterlet along their floors may be ring-dike or graben depressions formed peripherally on caldera floors similar to those associated with terrestrial caldera margins (for example, Aso (Japan), Valles (New Mexico), and Toba (Sumatra)) 6 .

Although most terrestrial sinuous valleys are formed by meandering streams, such streams are usually associated with extensive floodplains leading out from upland $V$ shaped erosional valleys. These and normal tributary drainage patterns are lacking on the Moon. Small lunar distributary systems could be lava crustal fractures ${ }^{7}$ of meandering lava channels. It is unlikely that sinuous rilles on the lunar lowlands would have been formed by water in the complete absence of erosional features by beams on the lunar highlands.

Cilvarry ${ }^{8}$ proposes that the mascon gravity anomalics are due to dense lake sediments in mare floors which were eroded fluvially from the lunar highlands. But lake sediments would be less dense than the surrounding area. Particles of low density are preferentially transported by streams out of the highlands. Thus lake sediments would have produced negative rather than positive gravity anomalies beneath the maria.

Hofstra University, Hempstead, NY.

\section{JULIAN KanE}

Gerald Carucci Barbara Turner JoAnne MCEnter

Garden City Senior High School, Garden City, NY.

Received April 8; revised August 1, 1969.

1 Muller, P. M., and Sjogren, W. L., Science, 161, 680 (1968).

2 Press, London, 1956).

s Campbell, M. J., O'Leary, B. T., and Sagan, C., Science, 164, 1273 (1969).

- Pcale, S. J., Schubert, G., and Lingenfelter, R. E., Nature, 220, 1223 (1968).

o'Kecfe. J. A., Science, 163, 670 (1969).

${ }^{\circ}$ Smith, R. L., in The Nature of the Lunar Surface (edit. by Hess, W. N.. Menze

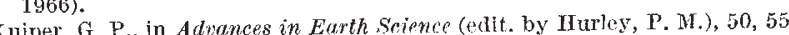

(MIT Press, Cambridge, Mass., 1966).

- Gilvarry, J. J., Nature, 221, 732 (1969).

\section{Lanthanides in the Silicate Inclusion of the Woodbine Meteorite}

The Woodbine iron meteorite is a rare type in that it contains 15.5 per cent of silicate inclusions ${ }^{1}$, which are different from the silicate phase of mesosideritc (pyroxeneplagioclase stony-iron), but resemble the chondrites in chemical and mineralogical composition.

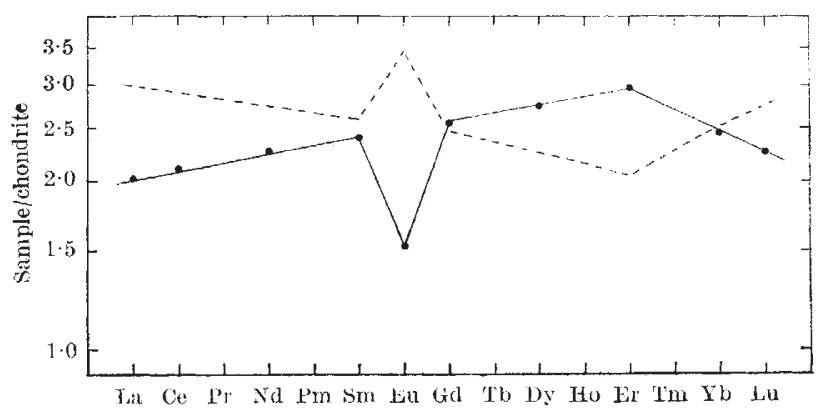

l'ig. 3. Chondrite-normalized lanthanide pattern of the silicatio inclusion in the Woodbine iron meteorite; the broken line shows a possible pattern for the lost counterpart, according to the second interpretation.

Silicate inclusion material weighing $235 \mathrm{mg}$ was analysed for lanthanides, and their abundances were determined by the isotope dilution technique ${ }^{2}$. Table 1 shows the result, and Fig. 1 the chondrite-normalized pattern; the lan. thanide abundances in the Modoc chondrite analysed by myself" were chosen as the base of the normalization in order to minimize systematic errors. Fig. I shows that the relative abundances of lanthanides in the Woodbine inclusion are different from those in chondrites. According to Schmitt et al.$^{3,4}$, the relative abundances of lanthanides in the silicate phase of two mesosiderites are substantially the same as in chondrites. (A more precise determination might reveal slight fractionations in mesosiderites too.) The Woodbine silicate material is also characteristic in showing a relative depletion of europium by a factor of 1.63 ; the silicate phase of mesosiderite does not show a europium depletion ${ }^{3,4}$. It therefore turns out that the silicate material in Woodbine is different from both the mesosiderite silicate phase and the chondrite. (As for the absolute concentration levels, the lanthanides in the Woodbine silicate material are close to those in the silicate phaso of the Estherville mesosiderite ${ }^{3}$.)

Table 1. LANTHANIDE ABUNDANCES (P.P.M.) IN THE SILICALE INCLUSTON OF THE WOOHBINE IROS METEORITE

\begin{tabular}{|c|c|}
\hline 0.758 & $\mathrm{Gd}$ \\
\hline 1.765 & Dy \\
\hline Na 1.58 & Ir \\
\hline Sm 0.520 & Yk \\
\hline Eu 0.107 & Lu \\
\hline
\end{tabular}

The chondrite-normalized lanthanide pattern might be interpreted in three ways. First, it might suggest that the inclusion reflects a solid material system scparated from a coexisting liquid. There can be a set of partition coefficients for lanthanides which has a maximum value around $\mathrm{Er}$ (refs. 5 and 6). But because of the rather chondritic chemical composition ${ }^{1}$ of Woodbine, it would be hard to consider this material as representing a solid system.

The pattern resembles that of a pyroxene fraction of the Juvinas eucrite studied by Philpotts et al. ${ }^{7}$ (see Fig. 2). except for the peak at $\mathbf{E r}$ for Woodbino. It is conceivable that an incomplete sorting of mineral grains took place in a molten nickel-iron due to differences in density and grain size. (The average grain size is about $0.2 \mathrm{~mm}$ (ref. 1).) A peak at Fr is not necessarily a serious difficulty for this second interpretation, because the partition into pyroxene reaches a naximum somewhore between Gr and Er, in 